\title{
A low profile wideband probe-fed dielectric resonator antenna
}

\author{
Yang Yu ${ }^{1}$, Jia Wang ${ }^{1}$, Wen-Wen Yang ${ }^{1,}$ a), Jing Xia ${ }^{2}$, Wei Qin ${ }^{1}$, and Jian-Xin Chen ${ }^{1}$
}

\begin{abstract}
Many approaches have been presented to broaden the impedance bandwidths of low profile dielectric resonator antennas (DRAs). However, few of them can achieve a balanced behaviour in terms of bandwidth, gain, radiation patterns, antenna size, etc. In this paper, a low profile wideband probe-fed DRA is proposed. By centrally placing a probe-fed strip DR in a $2 \times 2$ parasitic DR lattice, balanced antenna performance can be achieved. A DRA prototype was fabricated and tested for demonstration. Measured results show that the antenna can achieve an impedance bandwidth of $24 \%$, a peak gain of $7.92 \mathrm{dBi}$ with a compact DR size of $0.47 \times 0.47 \times 0.07 \lambda_{0}^{3}\left(\lambda_{0}\right.$ is the wavelength of the center frequency). Besides, symmetrical and consistent radiation patterns can be maintained within the band.

Keywords: dielectric resonator antenna, low-profile, wideband, probe-fed Classification: Microwave and millimeter-wave devices, circuits, and modules
\end{abstract}

\section{Introduction}

The dielectric resonator antenna (DRA) has been considered to be a good candidate for wireless communication systems due to its favourable characteristics, such as low loss, low cost and high design flexibility $[1,2,3,4,5,6,7,8,9,10,11$, $12,13,14,15]$. Considering the market demand for skinny and lightness devices, antennas with compact size and low profile will usually be more attractive [16, 17, 18, 19]. Recently, some interesting low profile DRA designs, known as dense dielectric patch antennas [20, 21, 22] and planar dielectric antennas [23], are developed to solve the traditional DRAs' bulky and low gain issues. However, owing to that high permittivity dielectric materials are introduced for achieving low antenna profiles, the radiation Q-factors become so high, leading to limited impedance bandwidths (typically less than 5\%) [22, 23].

Several approaches have been proposed to broaden the impedance bandwidth of low profile DRAs. In [24], the DRA mode and the feeding slot mode are skillfully combined to obtain a wide bandwidth of $10.49 \%$. However, the antenna gain is low $(<6.8 \mathrm{dBi})$ due to the slot radiation. In [25], by enlarging the length-to-height ratio of the DRA, the higher-order mode can be shifted down to merge with the fundamental mode and a bandwidth of $\sim 40 \%$ can be

\footnotetext{
${ }^{1}$ School of Information Science and Technology, Nantong University, Nantong, 226019, China

2 School of Computer Science and Communication Engineering, Jiangsu University, Zhenjiang, 212013, China

a)wwyang2008@ hotmail.com
}

DOI: 10.1587/elex.18.20200418

Received December 3, 2020

Accepted December 21, 2020

Publicized January 6, 2021

Copyedited January 25, 2021
Table I Performance comparison

\begin{tabular}{c|c|c|c|c|c}
\hline $\begin{array}{c}\text { DRA } \\
\text { ref. }\end{array}$ & $\begin{array}{c}\text { Excitation } \\
\text { method }\end{array}$ & $\begin{array}{c}\text { BW } \\
(\%)\end{array}$ & $\begin{array}{c}\text { Gain } \\
(\mathrm{dBi})\end{array}$ & $\begin{array}{c}\text { Overall DR } \\
\text { Size } \\
\left(\lambda_{0}^{3}\right)\end{array}$ & $\begin{array}{c}\text { Array } \\
\text { Applications }\end{array}$ \\
\hline$[24]$ & $\begin{array}{c}\text { Slot- } \\
\text { coupling }\end{array}$ & 10.49 & 6.75 & $0.5 \times 0.5 \times 0.04$ & Suitable \\
\hline$[25]$ & $\begin{array}{c}\text { Slot- } \\
\text { coupling }\end{array}$ & 40 & 10.5 & $0.77 \times 0.77 \times 0.1$ & Limited \\
\hline$[26]$ & $\begin{array}{c}\text { Slot- } \\
\text { coupling }\end{array}$ & 18.2 & 7.2 & $0.3 \times 0.3 \times 0.15$ & Suitable \\
\hline$[28]$ & $\begin{array}{c}\text { Slot- } \\
\text { coupling }\end{array}$ & 12 & 7.6 & $1.6 \times 0.2 \times 0.2$ & Limited \\
\hline $\begin{array}{c}\text { This } \\
\text { work }\end{array}$ & Probe-fed & 24 & 7.92 & $0.47 \times 0.47 \times 0.07$ & Suitable \\
\hline
\end{tabular}

achieved. Nevertheless, the antenna has a large planar DR size $\left(>0.77 \lambda_{0} \times 0.77 \lambda_{0}\right)$ that makes it unsuitable for many array applications. In [26], a stacked structure has been used to increase the antenna bandwidth to $18.2 \%$, but at the cost of a higher antenna profile. In [27, 28], the parasitic elements are used to enhance the DRA bandwidths. For instance, the bandwidth of DRA is increased $4.5 \%$ by using two parasitic elements in [27]. However, in these cases, the excited DR and the parasitic DRs are all arranged in line, resulting in rectangular overall DR structures with high length-towidth ratios. Such asymmetric structure not only degrades the antenna's radiation performance (such as very different E-plane and H-plane beam widths) but also limits its applications in two-dimensional antenna array. It is also worth mentioning that the slot-coupling feed scheme is adopted by all of the designs. Note that although slot-coupling is beneficial for the realization of broadband, it brings strong backward radiation. The probe-feed technique can be used to avoid this problem, and it can also greatly facilitate the integration of antennas with other microwave circuits. Actually, the probe-feed is preferred in many applications, such as Antenna-in-Package [29], vehicle mounted antenna [30], etc.

In this paper, we present a low profile wideband probefed DRA. By using a main strip DR and four parasitic DRs, two resonant modes can be excited to form a wide operating bandwidth. In contrast to linear arrangement, the strip DR is centrally placed in the $2 \times 2$ parasitic DR lattice, with two parasitic DRs on each side. The overall DRA structure is, thus, square and symmetric, yielding symmetrical radiation patterns. Table I lists the comparison of the proposed antenna with some state-of-the-art low profile DRAs. It can be seen that this design has a wider impedance bandwidth and a higher gain than that of $[19,21]$ and [23]. Compared to [20], the proposed antenna has a much more compact DR size, making it more suitable for array applications. 


\section{Antenna configuration and working principle}

The geometry of the proposed antenna is shown in Fig. 1. The radiation unit on the top consists of a main strip DR and four parasitic DRs. Specifically, the strip DR is centrally placed in the $2 \times 2$ parasitic DR lattice. All of the DRs are made of high permittivity ceramic materials but with $\varepsilon_{r 1}$ for the strip DR and $\varepsilon_{r 2}$ for the parasitic ones. Below them is Substrate $1\left(\mathrm{RO} 4003 \mathrm{C}, \varepsilon_{r}=3.38, \tan \delta=0.0027\right)$ which serves as a supporting board. Note that four small L-shaped metal strips are etched on the upper surface to facilitate the parasitic DRs' positioning and alignment. They can also, to some extent, help to suppress some spurious DR modes. On the bottom is a feeding microstrip line. It is printed on the back side of Substrate 2 (RO4003C), and connected to the feeding pad through a via.

The basic idea of this design is clear. The strip DR mode is excited firstly by the feed probe, and the $2 \times 2 \mathrm{DR}$ lattice is then parasitically coupled to the driven strip DR, producing additional mode for widening the bandwidth. The simulated E-field distributions at the two resonant frequencies are depicted in Fig. 2. It is found that, at a higher frequency, most of the E-fields are located in the parasitic DRs ( $\mathrm{TE}_{111}$ mode is excited for each parasitic DR), indicating that they are strongly coupled to the strip DR in this case. The resonance is then mostly influenced by the parasitic DRs. On the other hand, the lower frequency resonance is found to be mainly
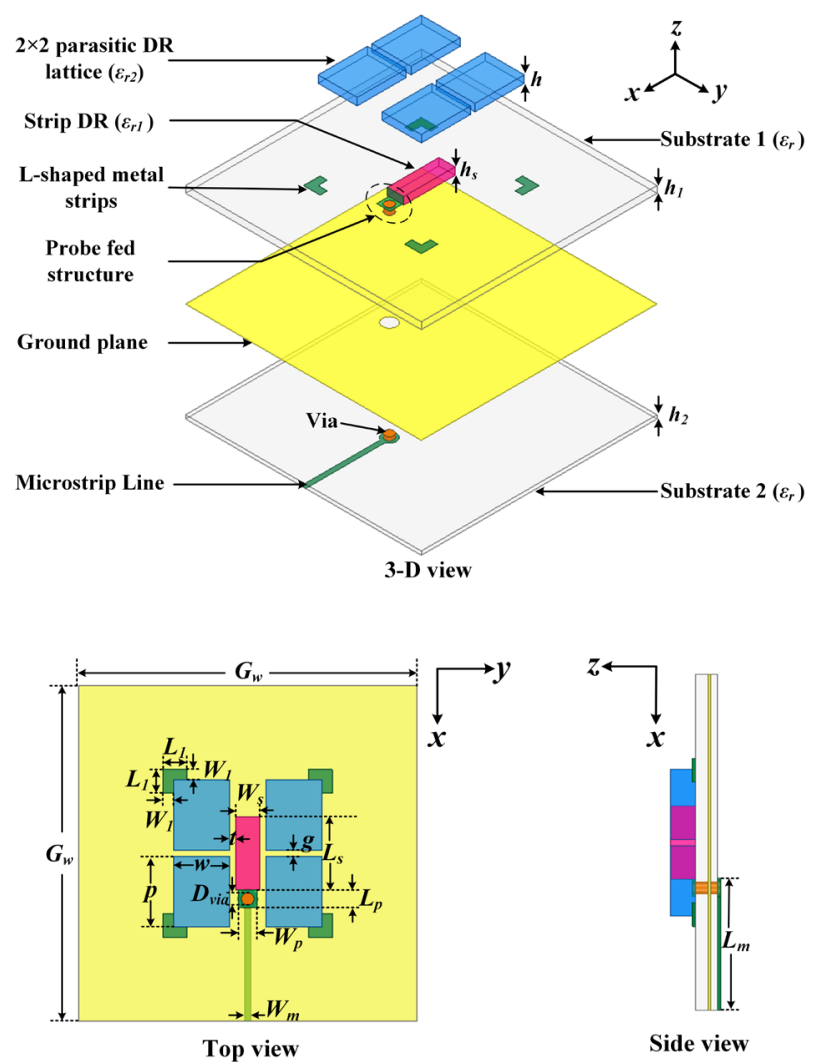

Fig. 1 Configuration of the proposed DRA $\left(G_{W}=32 \mathrm{~mm}, h_{1}=\right.$ $0.813 \mathrm{~mm}, h_{2}=0.305 \mathrm{~mm}, \varepsilon r_{1}=69, p=6.7 \mathrm{~mm}, g=0.6 \mathrm{~mm}$, $w=5.3 \mathrm{~mm}, h=1 \mathrm{~mm}, \varepsilon r_{2}=45, L_{s}=7 \mathrm{~mm}, W_{s}=2.2 \mathrm{~mm}$, $h_{s}=1 \mathrm{~mm}, t=0.6 \mathrm{~mm}, L_{1}=2.25 \mathrm{~mm}, W_{1}=1 \mathrm{~mm}, D_{v i a}=1.2 \mathrm{~mm}$, $\left.L_{m}=12.63 \mathrm{~mm}, W_{m}=0.65 \mathrm{~mm}, L_{p}=1.65 \mathrm{~mm}, W_{p}=1.8 \mathrm{~mm}\right)$ contributed by the strip DR as the E-fields are concentrated in the strip DR ( $\mathrm{TE}_{111}$ mode is excited). In Fig. 3, a comparative study of two antennas with different configurations has been done to further demonstrate the working principle. It can be found that even half of the parasitic DR lattice is removed, the coupling between strip DR and parasitic DRs still exists but with the gain degraded in high frequency band due to the reduced radiation aperture. Finally, it is worth noting that the radiation from the gaps between the DR blocks decreases the radiation $\mathrm{Q}$ factor of the DRA, which can further facilitating the bandwidth enhancement.

Parametric studies have been carried out to characterize the design. Fig. 4 shows the reflection coefficients for different heights $\left(h_{s}\right)$ of the strip DR and lengths $(p)$ of the parasitic DRs. It can be observed that as $h_{s}$ increases, the lower

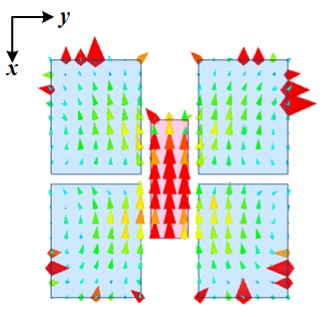

(a)

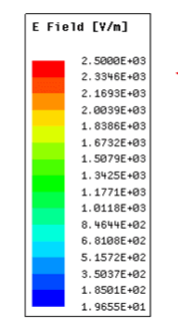

Fig. 2 E-field distributions of the DRA at two resonant frequencies. (a) At $9.4 \mathrm{GHz},($ b) at $10.6 \mathrm{GHz}$

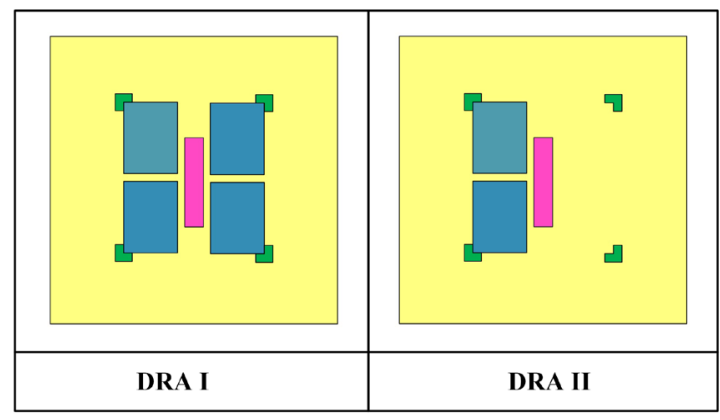

DRA I: with $2 \times 2$ parasitic DR lattice

DRA II: with $2 \times 1$ parasitic DR lattice

(a)

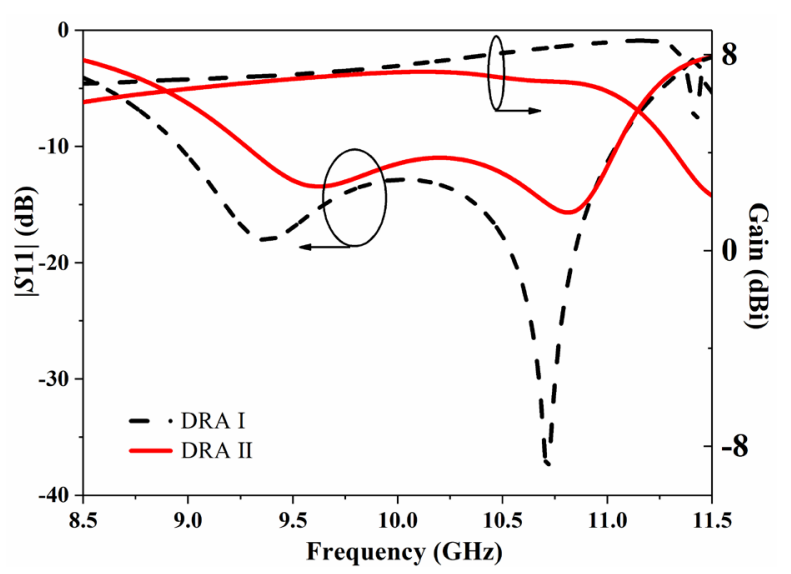

(b)

Fig. 3 A comparative study of two kinds of antennas. (a) Two antenna configurations: DRA I and DRA II, (b) simulated results of the two antennas 


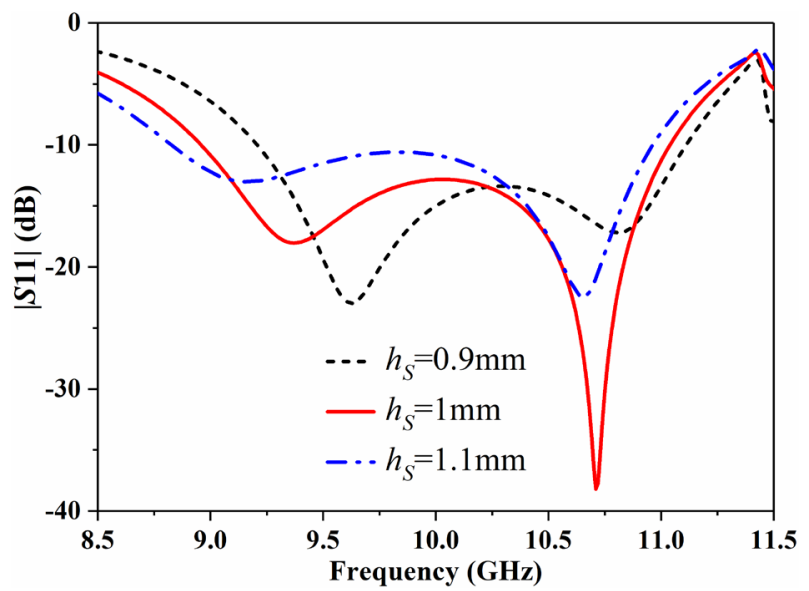

(a)

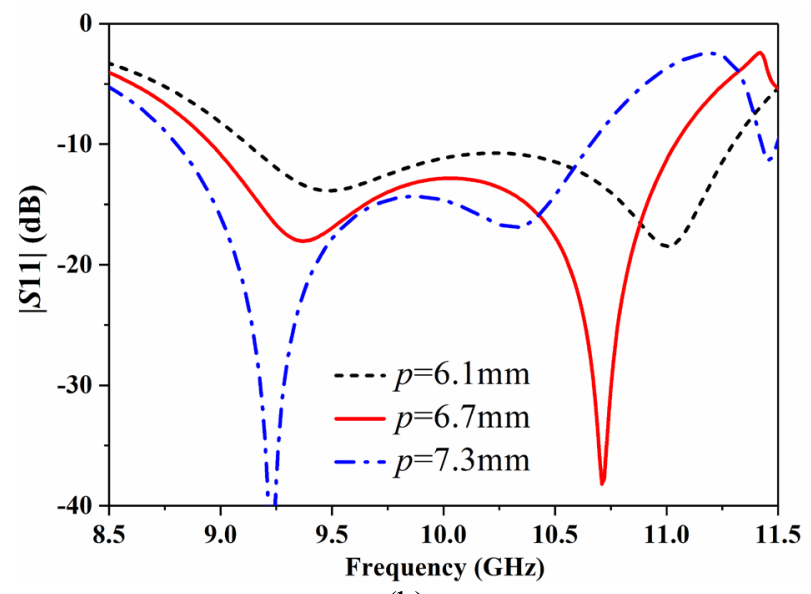

(b)

Fig. 4 Simulated $|\mathrm{S} 11|$ for different parameters. (a) Height $\left(h_{s}\right)$ of the strip DR, (b) length $(p)$ of the parasitic DRs

resonant frequency shifts down, while the higher resonant frequency stays unchanged. When increasing $p$, the higher resonant frequency decreases while the lower resonant frequency remains relatively stable. These results verify that the lower frequency resonance is mainly contributed by the strip DR, while the higher one is caused by the parasitic DR lattice.

\section{Experimental results}

To validate the design concepts, an antenna prototype was fabricated and measured. The simulated and measured reflection coefficients and gains of the antenna are shown in Fig. 5. The measured impedance bandwidth for $|\mathrm{S} 11|<-10$ $\mathrm{dB}$ is $24 \%$, from $8.99 \mathrm{GHz}$ to $11.43 \mathrm{GHz}$. A measured peak gain of $7.92 \mathrm{dBi}$ is achieved at $10.7 \mathrm{GHz}$. Fig. 6 depicts the radiation patterns at two resonant frequencies of 9.4 and 10.6 GHz. It is found that the antenna radiates in a broadside direction with symmetrical radiation patterns and consistent E-plane and H-plane beam widths.

\section{Conclusion}

In this paper, a technique to design a low profile wideband probe-fed DRA has been presented. The dual-mode op-

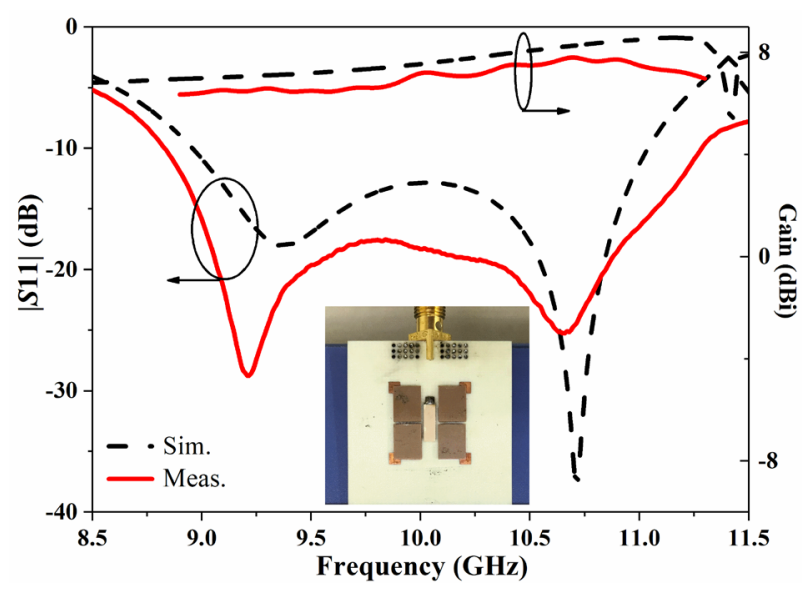

Fig. 5 Simulated and measured $|\mathrm{S} 11|$ and gains of the antenna

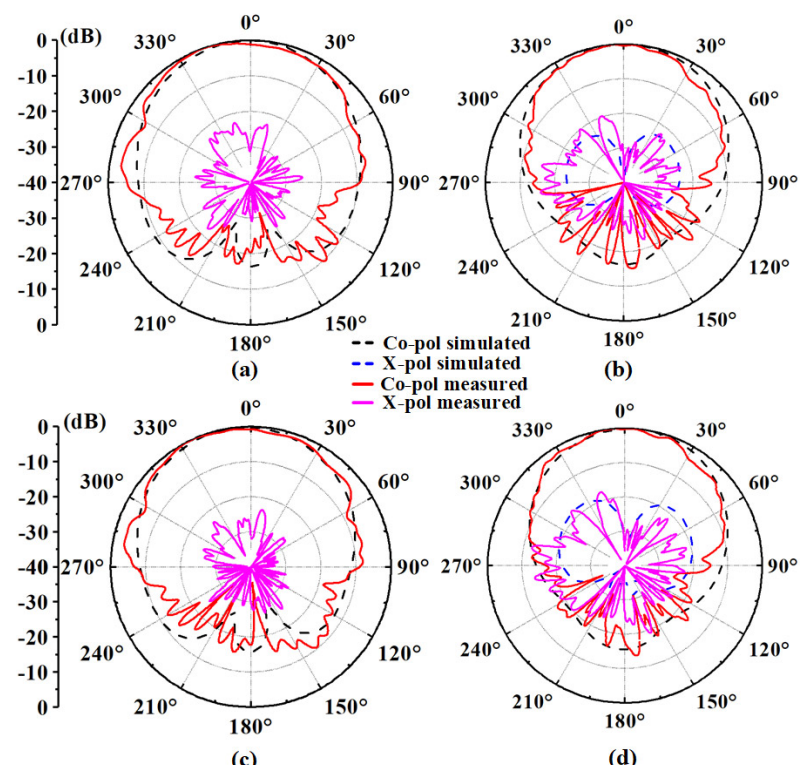

Fig. 6 Simulated and measured radiation patterns of the antenna. (a) At $9.6 \mathrm{GHz}$, E-plane, (b) at $9.6 \mathrm{GHz}, \mathrm{H}$-plane, (c) at $10.4 \mathrm{GHz}$, E-plane, (d) at $10.4 \mathrm{GHz}, \mathrm{H}-$ plane

erating principle is studied firstly followed by a parametric analysis. Compared to the state-of-the-art low profile DRAs, the antenna combines some valuable features of wide bandwidth, high gain, compact size, symmetrical and consistent radiation patterns, making it an attractive candidate for future wireless communication system applications.

\section{Acknowledgments}

The work was supported by the National Natural Science Foundation of China under grants 62071256 and 61971244, and also by Natural Science Foundation of Jiangsu Province (Grant No. BK20161281).

\section{References}

[1] K.W. Leung, et al.: "Dielectric resonator antennas: From the basic to the aesthetic," Proc. IEEE 100 (2012) 2181 (DOI: 10.1109/JPROC. 2012.2187872).

[2] S. Long, et al.: "The resonant cylindrical dielectric cavity antenna," IEEE Trans. Antennas Propag. 31 (1983) 406 (DOI: 10.1109/TAP. 
1983.1143080).

[3] Q. Lai, et al.: "Comparison of the radiation efficiency for the dielectric resonator antenna and the microstrip antenna at ka band," IEEE Trans. Antennas Propag. 56 (2008) 3589 (DOI: 10.1109/TAP. 2008.2005551).

[4] R.K. Mongia and A. Ittipiboon: "Theoretical and experimental investigations on rectangular dielectric resonator antennas," IEEE Trans. Antennas Propag. 45 (1997) 1348 (DOI: 10.1109/8.623123).

[5] A. Petosa and A. Ittipiboon: "Dielectric resonator antennas: a historical review and the current state of the art," IEEE Antennas Propag. Mag. 52 (2010) 91 (DOI: 10.1109/MAP.2010.5687510).

[6] K.-W. Leung, et al.: "Theory and experiment of an aperture coupled hemispherical dielectric resonator antenna," IEEE Trans. Antennas Propag. 43 (1995) 1192 (DOI: 10.1109/8.475090).

[7] M.W. McAllister and S.A. Long: "Resonant hemispherical dielectric antenna," IEEE Electron. Lett. 20 (1984) 657 (DOI: 10.1049/ el:19840450).

[8] R.K. Mongia, et al.: "Measurement of radiation efficiency of dielectric resonator antenna," IEEE Microw. Guided Wave Lett. 4 (1994) 80 (DOI: 10.1109/75.275587).

[9] R.A. Karnenburg and S.A. Long: "Microstrip transmission line excitation of dielectric resonator antennas," Electron. Lett. 24 (1988) 1156 (DOI: 10.1049/el:19880785).

[10] A. Motevasselian, et al:: "A helix excited circularly polarized hollow cylindrical dielectric resonator antenna," IEEE Antennas Wireless Propag. Lett. 12 (2013) 535 (DOI: 10.1109/LAWP.2013.2257942).

[11] K.W. Leung, et al.: "Dual-function radiating glass for antennas and light covers-part II: dual-band glass dielectric resonator antennas," IEEE Trans. Antennas Propag. 62 (2013) 587 (DOI: 10.1109/TAP.2012.2216496).

[12] D.M. Pozar and B. Kaufman: "Comparison of three methods for the measurement of printed antenna efficiency," IEEE Trans. Antennas Propag. 36 (1988) 136 (DOI: 10.1109/8.1084).

[13] M. Amin, et al.: "Gain enhancement in cubic DRA with modified microstrip feed for WLAN applications," IEICE Electron. Express 14 (2017) 20170960 (DOI: 10.1587/elex.14.20170960).

[14] J.-B. Yan and J.T. Bernhard: "Implementation of a frequency-agile MIMO dielectric resonator antenna," IEEE Trans. Antennas Propag. 61 (2013) 3434 (DOI: 10.1109/TAP.2013.2255092).

[15] Y.-M. Pan, et al.: "Compact quasi-isotropic dielectric resonator antenna with small ground plane," IEEE Trans. Antennas Propag. 62 (2014) 577 (DOI: 10.1109/TAP.2013.2292082).

[16] W. Hong, et al:: "Millimeter-wave 5G antennas for smartphones: overview and experimental demonstration," IEEE Trans. Antennas Propag. 65 (2017) 6250 (DOI: 10.1109/TAP.2017.2740963).

[17] L. Guo and K.W. Leung: "Compact unilateral circularly polarized dielectric resonator antenna," IEEE Trans. Antennas Propag. 66 (2018) 668 (DOI: 10.1109/TAP.2017.2786346).

[18] E. Tammam, et al.: "Design of a compact size UWB planar antenna with WiMAX band rejection," IEICE Electron. Express 9 (2012) 1304 (DOI: 10.1587/elex.9.1304).

[19] T. Moriyama, et al.: "Planar multiband antenna for 3G/4G advanced wireless services," IEICE Electron. Express 11 (2014) 20140570 (DOI: 10.1587/elex.11.20140570).

[20] Y. Li and K.-M. Luk: "Wideband perforated dense dielectric patch antenna array for millimeter-wave applications," IEEE Trans. Antennas Propag. 63 (2015) 3780 (DOI: 10.1109/TAP.2015.2441118).

[21] H.W. Lai, et al.: "Dense dielectric patch antenna - a new kind of low-profile antenna element for wireless communications," IEEE Trans. Antennas Propag. 61 (2013) 4239 (DOI: 10.1109/TAP.2013. 2260122).

[22] O.M. Haraz, et al:: "Dense dielectric patch array antenna with improved radiation characteristics using EBG ground structure and dielectric superstrate for future 5G cellular networks," IEEE Access 2 (2014) 909 (DOI: 10.1109/ACCESS.2014.2352679).

[23] A. Rashidian, et al.: "Printable planar dielectric antennas," IEEE Trans. Antennas Propag. 64 (2016) 403 (DOI: 10.1109/TAP.2015. 2502265).

[24] Y. Liu, et al.: "A low-profile and high-permittivity dielectric resonator antenna with enhanced bandwidth," IEEE Antennas Wireless Propag. Lett. 14 (2014) 791 (DOI: 10.1109/LAWP.2014.2385862).
[25] Y.M. Pan and S.Y. Zheng: "A low-profile stacked dielectric resonator antenna with high-gain and wide bandwidth," IEEE Antennas Wireless Propag. Lett. 15 (2016) 68 (DOI: 10.1109/LAWP.2015.2429686).

[26] W.-J. Sun, et al.: "Stacked dielectric patch resonator antenna with wide bandwidth and flat gain," J. Eng. 2018 (2018) 336 (DOI: 10.1049/joe.2017.0859).

[27] Z. Fan, et al.: "Parasitic coplanar three-element dielectric resonator antenna subarray," Electron. Lett. 32 (1996) 789 (DOI: 10.1049/el:19960514).

[28] W.M. Abdel-Wahab, et al.: "SIW-integrated parasitic DRA array: analysis, design, and measurement," IEEE Antennas Wireless Propag. Lett. 18 (2019) 69 (DOI: 10.1109/LAWP.2018.2880926).

[29] D. Liu, et al.: "Antenna-in-package design considerations for Ka-band 5G communication applications," IEEE Trans. Antennas Propag. 65 (2017) 6372 (DOI: 10.1109/TAP.2017.2722873).

[30] K.W. Leung: "Conformal strip excitation of dielectric resonator antenna," IEEE Trans. Antennas Propag. 48 (2000) 961 (DOI: 10.1109/8.865230). 